\title{
Evaluation of a Method for Remote Detection of Fuel Relocation Outside the Original Core Volumes of Fukushima Reactor Units 1-3
}

\section{ICONE 20-POWER2012}

\section{Douglas W. Akers}

Edwin A. Harvego

The INL is a

U.S. Department of Energy

National Laboratory

operated by

Battelle Energy Alliance

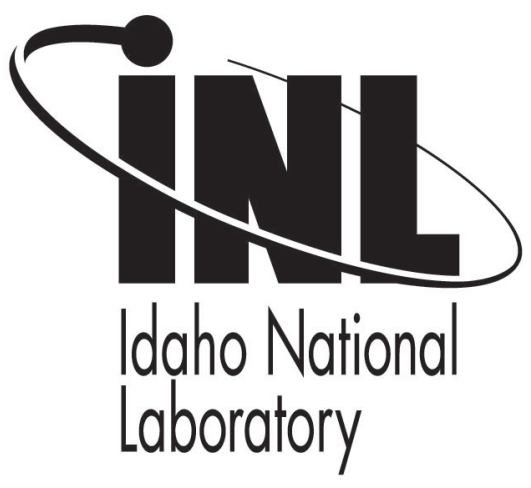

This is a preprint of a paper intended for publication in a journal or proceedings. Since changes may be made before publication, this preprint should not be cited or reproduced without permission of the author. This document was prepared as an account of work sponsored by an agency of the United States Government. Neither the United States Government nor any agency thereof, or any of their employees, makes any warranty, expressed or implied, or assumes any legal liability or responsibility for any third party's use, or the results of such use, of any information, apparatus, product or process disclosed in this report, or represents that its use by such third party would not infringe privately owned rights. The views expressed in this paper are not necessarily those of the United States Government or the sponsoring agency. 


\section{ICONE20POWER2012-54528}

\section{EVALUATION OF A METHOD FOR REMOTE DETECTION OF FUEL RELOCATION OUTSIDE THE ORIGINAL CORE VOLUMES OF FUKUSHIMA REACTOR UNITS 1-3}

\author{
Douglas W. Akers \\ Idaho National Laboratory \\ Idaho Falls, Idaho, U.S.A.
}

\author{
Edwin A. Harvego \\ Idaho National Laboratory \\ Idaho Falls, Idaho, U.S.A.
}

\section{ABSTRACT}

This paper presents the results of a study to evaluate the feasibility of remotely detecting and quantifying fuel relocation from the core to the lower head, and to regions outside the reactor vessel primary containment of the Fukushima 1-3 reactors. The goals of this study were to determine measurement conditions and requirements, and to perform initial radiation transport sensitivity analyses for several potential measurement locations inside the reactor building. The radiation transport sensitivity analyses were performed based on reactor design information for boiling water reactors (BWRs) similar to the Fukushima reactors, ORIGEN2 analyses of 3-cycle BWR fuel inventories, and data on previously molten fuel characteristics from TMI- 2. A $100 \mathrm{~kg}$ mass of previously molten fuel material located on the lower head of the reactor vessel was chosen as a fuel interrogation sensitivity target. Two measurement locations were chosen for the transport analyses, one inside the drywell and one outside the concrete biological shield surrounding the drywell. Results of these initial radiation transport analyses indicate that the $100 \mathrm{~kg}$ of previously molten fuel material may be detectable at the measurement location inside the drywell, but that it is highly unlikely that any amount of fuel material inside the reactor pressure vessel will be detectable from a location outside the concrete biological shield surrounding the drywell. Three additional fuel relocation scenarios were also analyzed to assess detection sensitivity for varying amount of relocated material in the lower head of the reactor vessel, in the control rods perpendicular to the detector system, and on the lower head of the drywell. Results of these analyses along with an assessment of background radiation effects and a discussion of measurement issues are included in the paper.

\author{
FSAR Final Safety Analysis Report \\ GE General Electric Company \\ RPV Reactor pressure vessel \\ TMI-2 Three Mile Island Nuclear Reactor, Unit 2
}

\section{INTRODUCTION}

An initial assessment has been performed to determine the feasibility of quantifying fuel relocation outside the original core volumes of Fukushima reactors 1-3. The primary goals of this paper are to define the assumptions used for this analysis and to present initial radiation transport sensitivity analysis results for several potential measurement locations inside the reactor building. The physical geometry assumptions developed for this analysis are primarily based on a review of BWR Final Safety Analysis Reports (FSARS) for reactors with similar designs to Fukishima 1 (BWR 3 -Mark 1 Containment) and Fukishima 2-3 (BWR-4 Mark 1 Containment) as specific data for the Fukushima reactors was not available.

The Fukushima radiation transport calculations were performed based on the reactor design information obtained from the FSARs, ORIGEN2[1] analyses of 3-cycle BWR fuel inventories, and data on previously molten fuel characteristics from TMI-2. These initial transport calculations were performed using MicroShield [2], a standard photon transport and shielding code, although more sophisticated codes that require more detailed setup may be used in subsequent analyses. The following sections summarize the physical geometry assumptions used, the radiation transport modeling assumptions and the initial transport analysis results for possible measurement locations outside the concrete biological shield surrounding the drywell and in the drywell below the reactor core.

\section{NOMENCLATURE}

BWR Boiling water reactor 


\section{PHYSICAL MODELING ASSUMPTIONS}

The physical modeling assumptions were based on FSAR drawings and information for similar reactor designs. Figure 1 shows a Mark 1 containment with access locations to the drywell and Figure 2 shows the drywell and reactor internals in addition to the 2 measurement locations for which the radiation-transport sensitivity analyses were performed. The measurement location outside the primary containment was chosen because the biological shield thickness surrounding the drywell is about $4 \mathrm{ft}(1.2 \mathrm{~m})$ of reinforced concrete in this area of the containment rather than the $6 \mathrm{ft}(1.83 \mathrm{~m})$ in other areas of the containment structure. The measurement location inside the primary containment structure was chosen because the personnel access hatch is at the $933 \mathrm{ft} 6$ in elevation and provides a direct measurement point located above the floor elevation that allows measurements to be performed from the lower head of the reactor vessel up to the core support plate (nominal elevation -968 ft) with the lowest amount of intervening material present. It should be noted that some lower head locations may be obstructed by control rod drives, vessel penetrations, and piping. For this initial analysis, control rods and lower head penetrations have not been included, as gaps between the control rod assemblies that may allow direct access to the lower head are likely present.

Table 1 summarizes the BWR 3 and 4 reactor physical geometry assumptions used to perform the radiation transport calculations. These assumptions are based on average values in some cases for several reactors designs but are expected to be representative of the Fukushima reactors. For this analysis, the primary components between the nominal source location inside the reactor vessel and the detector system located either outside the primary containment or inside the drywall are: 1) the reactor pressure vessel (RPV) wall, 2) the sacrificial shield used to prevent gamma heating of the drywell, 3) the primary containment steel liner and the concrete primary containment biological shield. The dimensions of these components and their densities are based on available information.

\section{RADIATION TRANSPORT ANALYSIS}

The Fukushima radiation transport sensitivity analyses were performed based on the reactor design information obtained from the FSARs, ORIGEN2 analyses of 3-cycle BWR fuel inventories, and data on previously molten fuel characteristics from TMI- 2. The ORIGEN2 calculations were performed based on a generic GE BWR-4 assembly with an initial average enrichment of $3.0 \mathrm{wt} \% 235 \mathrm{U}$ after irradiation for four 300-day cycles to an exposure of $33 \mathrm{GWd} / \mathrm{MTU}$. Although this assumption may not be accurate for each of the Fukushima reactors it provides an initial basis for assessing radiation transport to radiation measurement systems outside the primary containment or in the drywell.

To determine the source term in previously molten fuel that would likely be transported to locations below the core support plate, the fission product inventory for a BWR-4 fuel assembly with the irradiation noted above was homogenized over the
Table 1. BWR 3 physical geometry and material densities.

\begin{tabular}{|c|c|}
\hline Component & Dimensions/density \\
\hline Inner RPV diameter, cm (ft) & $615.6(20.2)$ \\
\hline Inner RPV radius, cm $(\mathrm{ft})$ & $307.8(10.1)$ \\
\hline RPV wall thickness, cm (ft) & $15.6(6.12)$ \\
\hline RPV wall density, $\mathrm{g} / \mathrm{cm}^{3}\left(\mathrm{lbs} / \mathrm{ft}^{3}\right)$ & $7.86(490)$ \\
\hline Sacrificial shield -inner plate, $\mathrm{cm}$ (in) & $1.9(0.75)$ \\
\hline $\begin{array}{l}\text { Sacrificial shield -IP density, } \mathrm{g} / \mathrm{cm}^{3} \\
\left(\mathrm{lbs} / \mathrm{ft}^{3}\right)\end{array}$ & $7.86(490)$ \\
\hline $\begin{array}{l}\text { Sacrificial shield -concrete layer, } \mathrm{cm} \\
\text { (in) }\end{array}$ & $53.3(21)$ \\
\hline $\begin{array}{l}\text { Sacrificial shield -Concrete density, } \\
\mathrm{g} / \mathrm{cm}^{3}\left(\mathrm{lb} / \mathrm{ft}^{3}\right)\end{array}$ & $2.32(145)$ \\
\hline $\begin{array}{l}\text { Sacrificial shield -outer steel layer, } \\
\text { cm (in) }\end{array}$ & $3.8(1.5)$ \\
\hline $\begin{array}{l}\text { Sacrificial shield -OP density, } \mathrm{g} / \mathrm{cm}^{3} \\
\left(\mathrm{lb} / \mathrm{ft}^{3}\right)\end{array}$ & $7.86(490)$ \\
\hline drywell radius, $\mathrm{cm}(\mathrm{ft})$ & $944.9(31)$ \\
\hline $\begin{array}{l}\text { Air gap outside SS to drywell wall, } \\
\mathrm{cm}(\mathrm{ft})\end{array}$ & $254.5(8.33)$ \\
\hline \multicolumn{2}{|l|}{ Detector location } \\
\hline Mid-point of air gap, cm (ft) & $126.9(4.165)$ \\
\hline $\begin{array}{l}\text { Distance from detector to source } \\
\text { location, } \mathrm{cm}(\mathrm{ft})\end{array}$ & $985(32.3)$ \\
\hline $\begin{array}{l}\text { Angle from } 933 \mathrm{ft} \text { floor to source, } \\
\text { degrees }\end{array}$ & 60.8 \\
\hline $\begin{array}{l}\text { Containment steel shell (spherical } \\
\text { portion, nominal), cm (in) }\end{array}$ & $2.86(1.125)$ \\
\hline $\begin{array}{l}\text { Primary containment biological } \\
\text { shield wall thickness, } \mathrm{m}(\mathrm{ft})\end{array}$ & $1.22(4.0)$ \\
\hline
\end{tabular}

mass of a nominal fuel assembly weight (680 lbs), which would produce previously molten fuel in the form of a $(\mathrm{U}, \mathrm{Zr}) \mathrm{O} 2$ ceramic material that would be expected to have similar characteristics to the previously molten debris on the lower head of the TMI-2 reactor. The TMI-2 lower head debris had a density of $8.4+/-0.6 \mathrm{~g} / \mathrm{cm}^{3}$, which was used for this analysis. The physical geometry used for this analysis was for $100 \mathrm{~kg}$ of previously molten fuel in a spherical geometry (radius $=14.13$ $\mathrm{cm}$ ) located on the lower head of the reactor vessel.

The primary radionuclide addressed in this analysis was 144Ce-Pr, which has a relatively high fission yield and relatively long half-life (284.3 days). This radionuclide is quantitatively retained with fuel material as demonstrated in TMI-2 research and was used for assessing the quantities of fuel present in TMI-2 debris. The concentration of the $144 \mathrm{Ce}-$ Pr varies as a function of burnup; however, it is not more than a factor of 2 in high burnup reactor cores, which is within the expected uncertainties for this type of assessment. The effects of background from other radionuclides present in the previously molten fuel have not been included in this scoping analysis. Table 2 lists the gamma rays and branching ratios used for the analysis. As indicated, the primary gamma ray 
with the highest penetration capability is the $2185.66 \mathrm{keV}$ gamma-ray line.

The $100 \mathrm{~kg}$ mass of fuel material was chosen as a fuel interrogation sensitivity target, because similar masses of fuel material may be of concern for defueling below the core volume of the reactor. Large volumes of fuel material and

Table 2. Pr-144 branching ratios

\begin{tabular}{|l|l|}
\hline Energy $(\mathrm{keV})$ & Branching ratio (\%) \\
\hline 696.5 & 1.342 \\
\hline 1489.16 & 0.278 \\
\hline 2185.66 & 0.694 \\
\hline
\end{tabular}

different distributions for different relocation scenarios are discussed in the following section. These simplified geometries were chosen arbitrarily to provide a basis for assessing detection limits and the likely sensitivity of this approach for larger volumes of fuel debris. However, it should be noted that the mean-free path of the $2185 \mathrm{keV}$ gamma ray line in previously molten fuel material is relatively limited so that $<1 \%$ of the $2185 \mathrm{keV}$ photons generated by the $144 \mathrm{Ce}-\mathrm{Pr}$ will escape a layer of debris $18 \mathrm{~cm}$ thick. Consequently most measurable activity comes from within the outer $18 \mathrm{~cm}$ of debris, which defines the thickness of the layer of debris that can be measured using this approach (i.e., thicker layers of debris would not be detectable) .

The radiation transport analyses were performed for the two detector locations shown in Figure 2 using all of the geometry and radiation transport data discussed above. It should be noted that in both cases, the detector is elevated above the floor level to allow direct measurements through the sacrificial shield. Results of the radiation transport analysis for the measurement location inside the drywell indicates that an uncollided flux of $2185 \mathrm{keV}$ photons on the order of 1 photon $/ \mathrm{cm} 2 / \mathrm{s}$ is present. These data suggest that with an appropriate detector/collimator design and if background effects can be minimized that it will be possible to perform fuel interrogation measurements at this location in the drywell. Further analyses need to be performed to address the detector/collimator design and background issues that may affect the sensitivity of the fuel interrogation measurements along with addressing larger volumes of material that are more widely distributed on the lower head of the reactor vessel.

Fuel relocation analyses were also performed for a measurement location outside the primary containment as shown in Figure 2. The additional reactor components between the detector system and the fuel material at the measurement location are the $4 \mathrm{ft}$ concrete biological shield surrounding the primary containment and the 1.125 in steel boundary. Results of this transport analysis indicate that uncollided photon flux levels are $<1 \mathrm{E}-4 \mathrm{p} / \mathrm{s} / \mathrm{cm}^{2}$ lower than those calculated for the location inside the drywell. This would indicate that it is highly unlikely that the $2,185 \mathrm{keV}$ gamma-ray line would be detectable. Furthermore, the gross radiation field outside the primary containment would also be expected to be virtually undetectable and highly affected by any contamination present either inside or outside the primary containment structure.

\section{LARGE VOLUME FUEL RELOCATION SCENARIOS}

Three additional fuel relocation scenarios have been analyzed to assess detection sensitivity in these three locations. The three scenarios are: 1) a layer of debris 7 in $(18 \mathrm{~cm})$ thick on the lower head of the reactor vessel, 2) a $100 \mathrm{~kg}$ mass of relocated fuel in the control rods perpendicular to the detector system and 3$)$ a layer of 7 in $(18 \mathrm{~cm})$ of debris on the lower head of the drywell. Figure 3 shows the source locations for these 3 measurement scenarios. The primary assumptions for these three scenarios are the same as those listed in Table 1 with the exception of those items listed in Table 3.

Scenario \#1 - Debris Layer on Lower Head of the RPV - A layer of relocated fuel debris 7 in $(18 \mathrm{~cm})$ thick was relocated to the lower head of the RPV. The thickness of the debris was chosen as that is the maximum mean free path for the $2185 \mathrm{keV}$ gamma ray line from $144 \mathrm{Ce}$-Pr being used for this analysis. The volume of debris located on the lower head would be about $3.4 \mathrm{E}+6 \mathrm{~cm}^{3}\left(3.4 \mathrm{~m}^{3}\right)$ and the mass about 28,600 $\mathrm{kg}$. This analysis assumes the maximum thickness of a layer of debris distributed over the lower head $(18 \mathrm{~cm})$ that could be detected (i.e., thicker layers of debris would not be detectable as the mean free path would be exceeded). The measurable flux for this geometry is about 130 photons $/ \mathrm{cm} 2 / \mathrm{s}$, which should be detectable and quantifiable. Also it should be possible to discriminate this amount of fuel from smaller amounts that might be located on the head of the reactor, because of the relatively high count rate from a full layer of debris on the lower head.

Scenario \#2 - $100 \mathrm{Kg}$ Relocated Fuel in the Control Rods Perpendicular to the Detector Location - This scenario is a $100 \mathrm{~kg}$ relocated ball of fuel material located in the control rods below the RPV. The physical geometry below the lower head of the reactor vessel is considerably different from that in the vicinity of the RPV. The primary difference is that measurements have to be performed through the pedestal, which is considerably thicker than the sacrificial shield located above the pedestal. The pedestal has a total thickness of 48 in $(121.9 \mathrm{~cm})$ whereas the sacrificial shield has a thickness of 23.25 in. $(59.055 \mathrm{~cm})$. However, the source is outside the RPV thereby eliminating the effects of the RPV wall on the response. The flux from the $2185 \mathrm{keV}$ gamma-ray line detectable at the measurement location is about 1 photons $/ \mathrm{cm} 2 / \mathrm{s}$, which should be detectable at this location without excessive difficulty.

Scenario \#3 - Debris on Lower Head of the Drywell - A layer of relocated fuel debris 7 in $(18 \mathrm{~cm})$ thick was relocated to the lower head of the drywell. The assumptions are similar to those used for the large volume of debris located on the lower head of the RPV. The volume of debris located on the lower head would be about $3.4 \mathrm{E}+6 \mathrm{~cm}^{3}\left(3.4 \mathrm{~m}^{3}\right)$ and the mass about $28,600 \mathrm{~kg}$. The measurable flux for this geometry is 
approximately 44 photons $/ \mathrm{cm}^{2} / \mathrm{s}$, which should be possible to detect and quantify in this geometry. Also because of the high count rate associated with this geometry it should be easy to discriminate this large amount of fuel from smaller amounts that might be located on the bottom of the drywell.

Table 3. Additional BWR physical geometry and material densities.

\begin{tabular}{|c|c|}
\hline Component & Dimensions/density \\
\hline Pedestal - inner plate (IP), cm (in) & $3.17(1.25)$ \\
\hline Pedestal - IP density, g/cm ${ }^{3}\left(\mathrm{lbs} / \mathrm{ft}^{3}\right)$ & $7.86(490)$ \\
\hline Pedestal - concrete layer, cm (in) & $118.11(46.5)$ \\
\hline $\begin{array}{l}\text { Pedestal - concrete density, } \mathrm{g} / \mathrm{cm}^{3} \\
\left(\mathrm{lbs} / \mathrm{ft}^{3}\right)\end{array}$ & $2.32(145)$ \\
\hline Pedestal - outer steel layer, cm (in) & $0.635(0.25)$ \\
\hline $\begin{array}{l}\text { Pedestal outer shield - density, } \mathrm{g} / \mathrm{cm}^{3} \\
\left(\mathrm{lbs} / \mathrm{ft}^{3}\right)\end{array}$ & $7.86(490)$ \\
\hline Drywell radius, $\mathrm{cm}(\mathrm{ft})$ & $944.9(31)$ \\
\hline $\begin{array}{l}\text { Air gap outside SS to drywell wall, cm } \\
\text { (ft) }\end{array}$ & $254.5(8.33)$ \\
\hline Mid point of air gap, $\mathrm{cm}(\mathrm{ft})$ & $126.9(4.165)$ \\
\hline Detector to $100 \mathrm{~kg}$ below RPV, cm (ft) & $472.4(15.5)$ \\
\hline $\begin{array}{l}\text { Detector to debris on floor of drywell, } \\
\mathrm{cm}(\mathrm{ft})\end{array}$ & $820.17(26.0)$ \\
\hline
\end{tabular}

\section{CONCLUSIONS}

A preliminary assessment of the feasibility of quantifying fuel relocation from the core to the lower head of the Fukushima 1-3 reactors has been completed. This paper described the assumptions used for these analyses and presented initial radiation transport sensitivity analysis results for several potential measurement locations inside the reactor building. The radiation transport sensitivity analyses were performed based on the reactor design information obtained from FSARs for reactors similar to the Fukushima reactors, ORIGEN2 analyses of 3-cycle BWR fuel inventories, and data on previously molten fuel characteristics from TMI- 2. A 100 $\mathrm{kg}$ mass of previously molten fuel material located on the lower head of the reactor vessel was chosen as a fuel interrogation sensitivity target. Two measurement locations were chosen for the transport analyses, one inside the drywell and one outside the containment. Results of these initial radiation transport analyses indicate that the $100 \mathrm{~kg}$ of previously molten fuel material would likely be detectable at the measurement location inside the drywell, but that it is highly unlikely that any amount of fuel material inside the RPV would be detectable from a location outside the concrete biological shield surrounding the drywell. A number of other fuel relocation scenarios, background radiation effects, and other measurement issues such as the detector/collimator design need to be addressed to provide a more definitive assessment of the ability of current radiation measurement systems and their sensitivity for detecting fuel relocation from the Fukushima reactor cores.

Three additional fuel relocation scenarios were also analyzed to assess detection sensitivity in these three locations. The three scenarios were: 1) a layer of debris 7 in $(18 \mathrm{~cm})$ thick on the lower head of the reactor vessel, 2) a $100 \mathrm{~kg}$ mass of relocated fuel in the control rods perpendicular to the detector system and 3) a layer of 7 in $(18 \mathrm{~cm})$ of debris on the lower head of the drywell. The results of these analyses indicate that all three relocation scenarios should produce detectable amounts of activity at the measurement location and that based on the relatively large fluxes detectable that it should be possible to discriminate different amounts of fuel at each location.

\section{ACKNOWLEDGMENTS}

This work was supported by the Idaho National Laboratory and by the U.S. Department of Energy, Office of Nuclear Energy.

\section{COPYRIGHT STATEMENT}

This manuscript has been authored by Battelle Energy Alliance, LLC under Contract No. DE-AC07-05ID14517 with the U.S. Department of Energy. The United States Government retains and the publisher, by accepting the article for publication, acknowledges that the United States Government retains a nonexclusive, paid-up, irrevocable, world-wide license to publish or reproduce the published form of this manuscript, or allow others to do so, for United States Government purposes.

\section{REFERENCES}

1. Cross, A. G., "ORIGEN2- A Revised and Updated Version of the Oak Ridge Isotope Generation and Depletion Code", ORNL-5621, July 1980

2. Grove Software, Inc., "MicroShield 9.XX", http://www.radiationsoftware.com/mshielddesc.pd f 


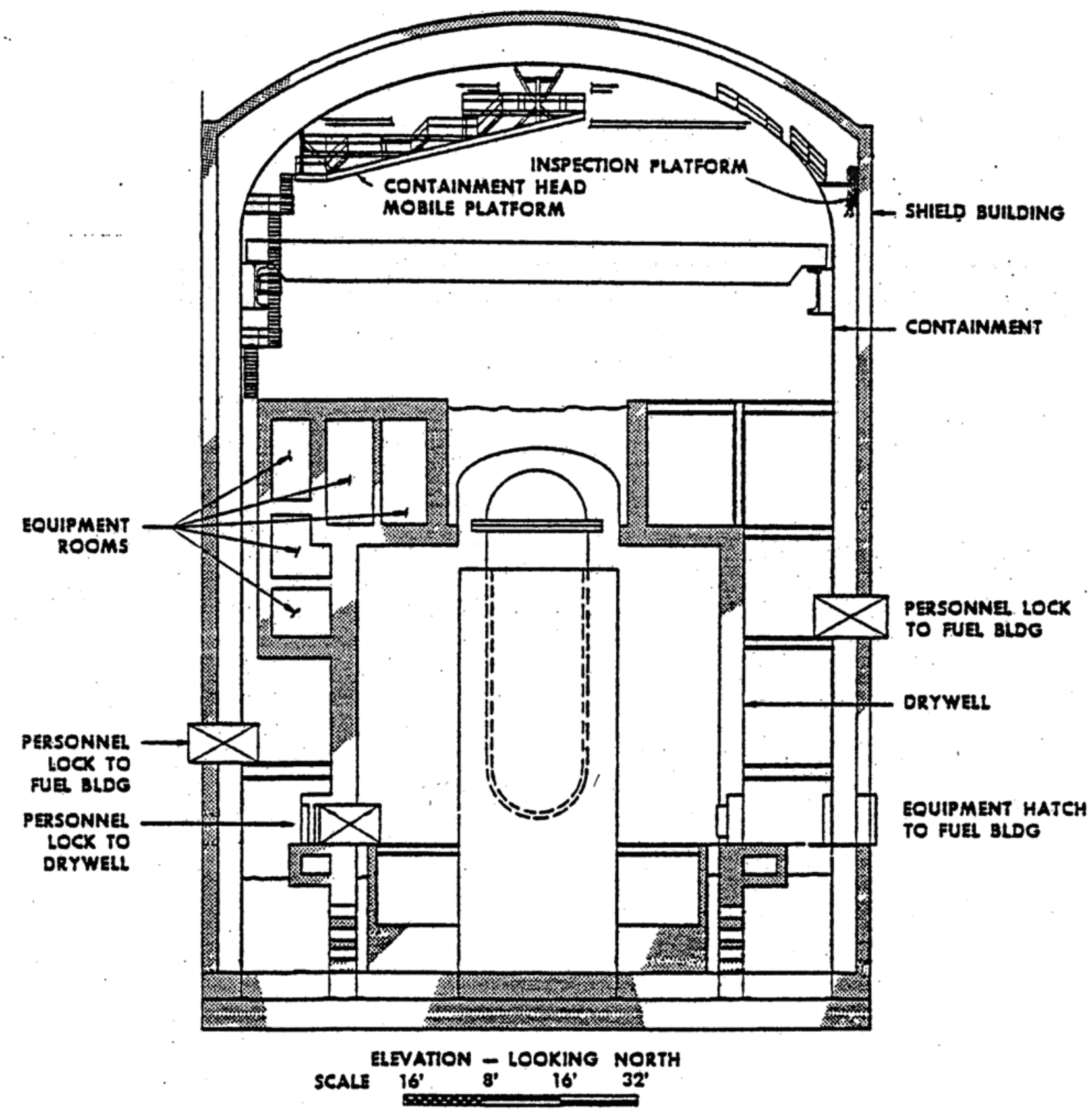

Figure 1. Drywell access locations (BWR Fundamentals - Mark I Containment-similar design to FSAR Descriptions) 


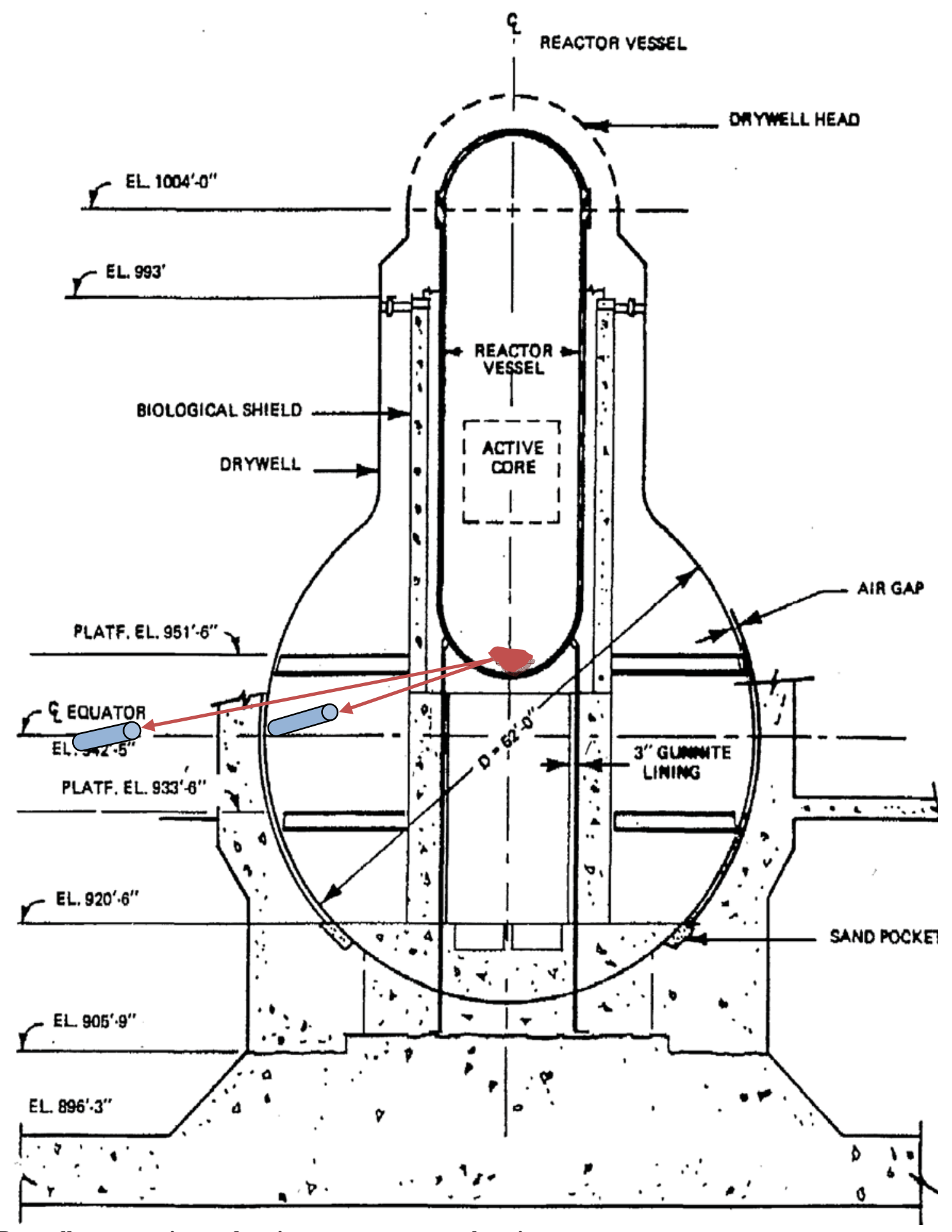

Figure 2. Drywell cross-section and optimum measurement locations. 


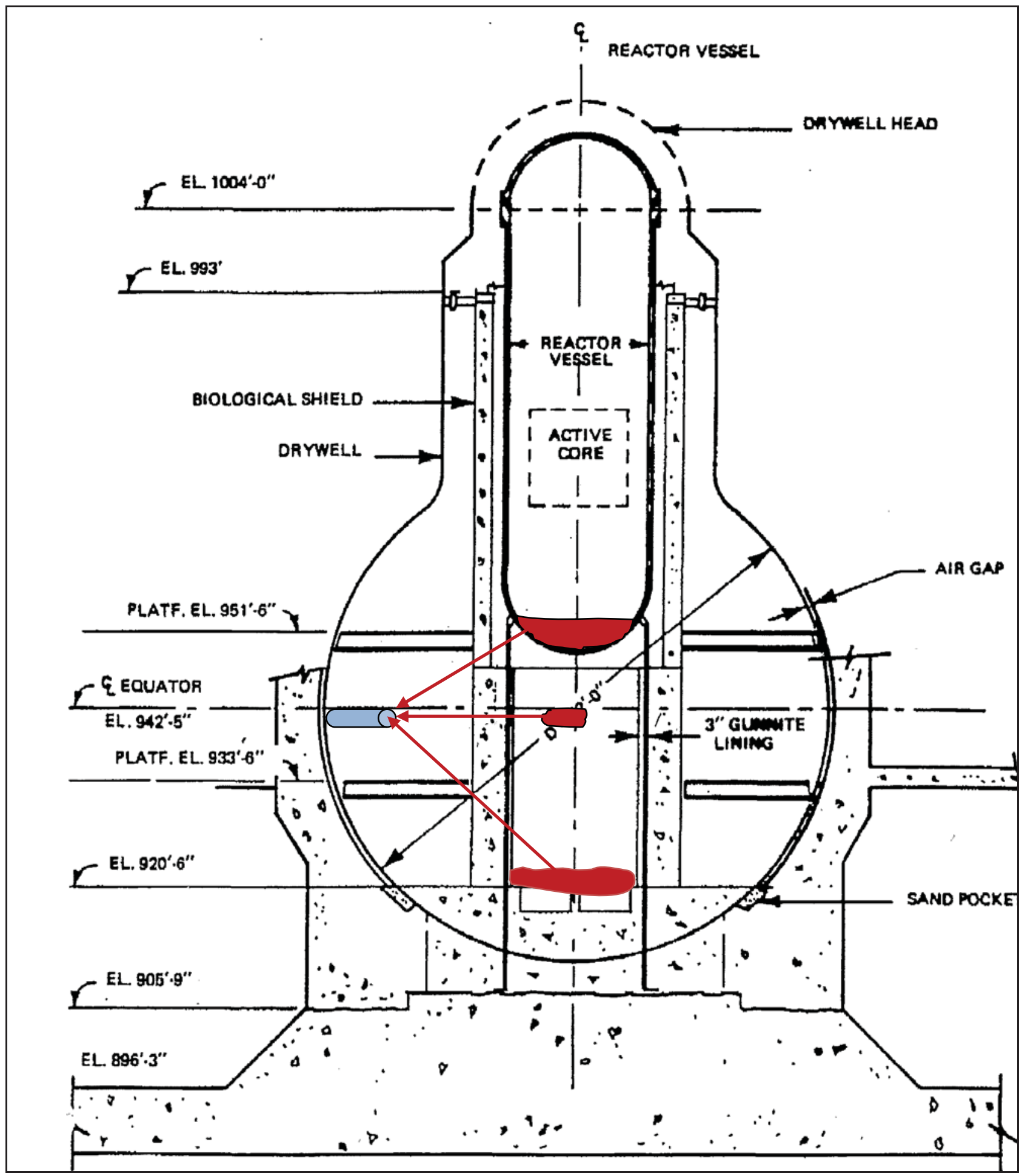

Figure 3. Drywell cross-section and three additional measurement locations. 